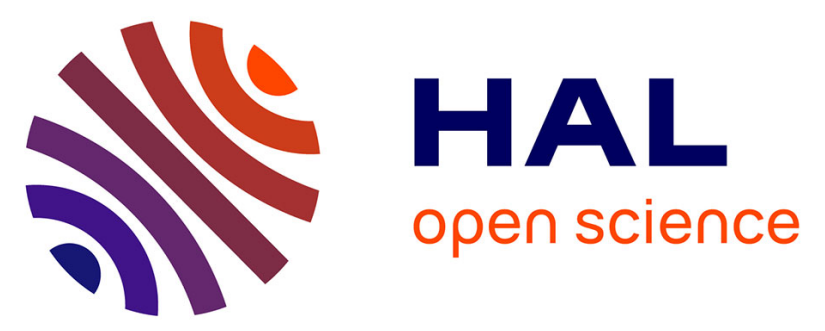

\title{
Development of a new screening method for the detection of antibiotic residues in muscle tissues using liquid chromatography and high resolution mass spectrometry with a LC-LTQ-Orbitrap instrument.
}

Dominique Hurtaud Pessel, Thota Jagadeshwar Reddy, Eric Verdon

\section{To cite this version:}

Dominique Hurtaud Pessel, Thota Jagadeshwar Reddy, Eric Verdon. Development of a new screening method for the detection of antibiotic residues in muscle tissues using liquid chromatography and high resolution mass spectrometry with a LC-LTQ-Orbitrap instrument.. Food Additives and Contaminants, 2011, 28 (10), pp.1340-1351. 10.1080/19440049.2011.605772 . hal-00743047

\author{
HAL Id: hal-00743047 \\ https://hal.science/hal-00743047
}

Submitted on 18 Oct 2012

HAL is a multi-disciplinary open access archive for the deposit and dissemination of scientific research documents, whether they are published or not. The documents may come from teaching and research institutions in France or abroad, or from public or private research centers.
L'archive ouverte pluridisciplinaire HAL, est destinée au dépôt et à la diffusion de documents scientifiques de niveau recherche, publiés ou non, émanant des établissements d'enseignement et de recherche français ou étrangers, des laboratoires publics ou privés. 


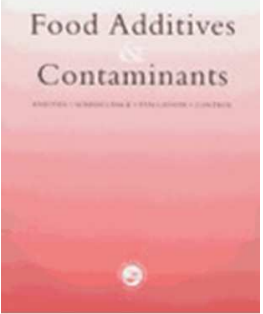

\section{Development of a new screening method for the detection of antibiotic residues in muscle tissues using liquid chromatography and high resolution mass spectrometry with a LC-LTQ-Orbitrap instrument.}

\begin{tabular}{|c|c|}
\hline Journal: & Food Additives and Contaminants \\
\hline Manuscript ID: & TFAC-2011-159.R1 \\
\hline Manuscript Type: & Special Issue \\
\hline $\begin{array}{r}\text { Date Submitted by the } \\
\text { Author: }\end{array}$ & $12-J u l-2011$ \\
\hline Complete List of Authors: & $\begin{array}{l}\text { HURTAUD PESSEL, Dominique; anses, Fougeres Laboratory, Unit } \\
\text { veterinary drug residues } \\
\text { Reddy, Thota; anses, Fougeres Laboratory, Unit veterinary drug residues } \\
\text { Verdon, Eric; anses, Fougeres Laboratory, Unit veterinary drug residues }\end{array}$ \\
\hline Methods/Techniques: & LC/MS \\
\hline Additives/Contaminants: & Veterinary drug residues - antibiotics \\
\hline Food Types: & Animal products - meat \\
\hline Abstract: & $\begin{array}{l}\text { In the present work, a liquid chromatography- high resolution mass } \\
\text { spectrometry method was developed for the screening in meat of a wide } \\
\text { range of antibiotics used in veterinary medicine. Full scan mode under } \\
\text { high resolution mass spectral conditions using LTQ-Orbitrap mass } \\
\text { spectrometer with resolving power } 60.000 \text { FWHM was applied for analysis } \\
\text { of the samples. Samples were prepared using two extractions protocols } \\
\text { prior to LC-MS analysis. The scope of the method focuses on the } \\
\text { screening of the following main families of antibacterial veterinary drugs: } \\
\text { penicillins, cephalosporins, sulphonamides, macrolides, tetracyclines, } \\
\text { aminoglucosides and quinolones. Compounds were successfully identified } \\
\text { in spiked samples by their accurate mass and LC retention times from the } \\
\text { acquired full-scan chromatogram. An automatic process of the data using } \\
\text { ToxId software allows a rapid treatment of the data. Analyses of muscle } \\
\text { tissues from real samples collected on antibiotic treated animals have } \\
\text { been carried out using the above methodology and antibiotic residues } \\
\text { have been identified unambiguously. Further analysis of the data of the } \\
\text { real samples allowed the identification of the targeted antibiotic residues } \\
\text { but also the non targeted compounds, such as some of their metabolites. }\end{array}$ \\
\hline
\end{tabular}




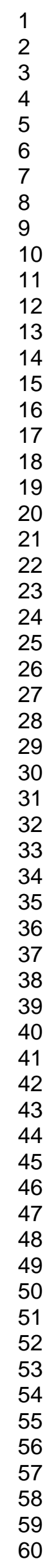

SCHOLARONE ${ }^{m}$

Manuscripts

10

11

12

14

15

16

18

19

20

22

23

25

26

27

29

30

33

34

35

36

39

40

41

43

44

45

46

47

48

49

50

52

53

54

56

57

58

60

http://mc.manuscriptcentral.com/tfac Email: fac@tandf.co.uk 


\title{
Development of a new screening method for the detection of antibiotic residues in muscle tissues using liquid chromatography and high resolution mass spectrometry with a LC-LTQ-Orbitrap instrument \\ D. Hurtaud-Pessel, T. Jagadeshwar Reddy, E. Verdon
}

Anses, French Agency for food, environmental and occupational health safety, Laboratory of Fougeres, Unit Veterinary Drug Residues, EU-RL for antibiotic and dye residues, La Haute Marche, Javené, BP 90203, 35302 Fougères, France

Corresponding author : dominique.pessel@anses.fr

Tel : +33299947878

Fax : +332999478 80

\begin{abstract}
A liquid chromatography- high resolution mass spectrometry (LC-HRMS) method was developed for screening meat for a wide range of antibiotics used in veterinary medicine. Full scan mode under high resolution mass spectral conditions using an LTQ-Orbitrap mass spectrometer with resolving power 60,000 full width at half maximum (FWHM) was applied for analysis of the samples. Samples were prepared using two extraction protocols prior to LC-HRMS analysis. The scope of the method focuses on screening the following main families of antibacterial veterinary drugs: penicillins, cephalosporins, sulfonamides, macrolides, tetracyclines, aminoglucosides and quinolones. Compounds were successfully identified in spiked samples from their accurate mass and LC retention times from the acquired full-scan chromatogram. Automated data processing using Toxld software allowed rapid treatment of the data. Analyses of muscle tissues from real samples collected from antibiotic treated animals was carried out using the above methodology and antibiotic residues were identified unambiguously. Further analysis of the data for real samples allowed the identification of the targeted antibiotic residues but also the non-targeted compounds, such as some of their metabolites.
\end{abstract}

Keywords: screening; antibacterials, high resolution; mass spectrometry; muscle tissue; residues; LTQ-Orbitrap 


\section{INTRODUCTION:}

Up to now, for screening residues in food of animal origin, antimicrobial agents used in veterinary medicine are mainly detected by microbiological assays, using the plate test bacterial growth inhibition technique, such as the four-plate test or the STAR test (Kilinc 2007, Pikkemaat 2009, Gaudin 2010). Microbiological methods offer a low cost analysis and do not require expensive equipment. However, due to their mode of detection, even if it is possible to identify one or more families of antibiotics using post-screening microbiological methods, they always lack specificity. It means that using such microbiological methods, it is not possible to discriminate one antibiotic from another. Moreover, they are quite often not sensitive enough to reach the maximum residue limits (MRLs) set by the Commission regulation (EU) 37/2010/EC.

It is well known that for confirmatory purpose in chemical residue testing, mass spectrometry is the technique of choice. A chemical approach based on mass spectrometric detection brings the specificity needed to chemically identify an antibiotic compound, even at the screening step. In the last decade, many analytical methods based on (very high pressure) liquid chromatography coupled to tandem mass spectrometry instruments (VHP) LC-MS/MS have been developed for multi-antimicrobial residue screening. (Granelli 2007, Kaufman, 2007, Bohm 2009, Gaugain-Juhel 2009). The use of HPLC (or U-HPLC) coupled to tandem MS combines chemical separation of analytes with the selectivity and the sensitivity of mass detection achieved in multiple reaction monitoring (MRM) mode. To enhance the confidence in the molecular identification, the analytes are usually detected by monitoring the ionic signal of at least two mass transitions, in combination with determining the chromatographic retention time. This approach is considered as a "pre-target screening" because analytes are pre-selected prior to their mass signal acquisition. This analytical technique in MRM mode needs selection of the compounds supposed to be monitored prior to the analysis and an optimization on each compound is necessary to fully determine the parameters of detection of their mass transitions (i.e. precursor ion, product ions, collision energy and voltages of the source). Consequently, only compounds included in the MRM method will be possibly detected, and other contaminants could never be detected even though they were actually present in the sample.

More recently, new approaches using high resolution mass spectrometry (HRMS) have been reported for screening residual compounds with equipment like time-of-flight mass detectors (TOF) or Orbital trap mass detectors (Orbitrap). These instruments allow full-scan acquisition of all signals obtained from the ionisation source, without pre-selecting any compounds. This approach in screening for trace amounts of chemicals is considered as a "post-target 
screening". Analytes are searched after their mass acquisition. The selectivity is obtained from a full scan acquisition of signals by extracting the ion chromatogram of the accurate mass of the target ions, thanks to filters based on narrow mass windows ( 3 to $20 \mathrm{ppm}$ ). This option also offers the possibility to retrospectively analyse the whole set of acquired data, without limitation in the number of compounds to be searched. This post-target approach has been applied recently for screening of marine toxins (Skrabakova 2010, Gerssen, 2011), pharmaceuticals in waste water (Petrovic 2006), veterinary drugs (Kaufmann, 2007 \& 2008; Ortelli, 2009; Peters 2009; Stolker 2008) or pesticides (Pico, 2007) in environmental matrices, in food, in biological areas and also for screening drug abuse in horse doping control (Moulard, 2010).

Non-target screening, looking for unknowns without any previous information on their chemical identity, can also be implemented from the full-scan mass acquisition data using the selectivity of high resolution mass spectrometry (HRMS) and adding the power of extractive/statistical software. Processing data from the full-scan chromatograms can eventually lead to extraction and chemical recognition of new biomarkers or trace compounds. This smart approach has recently been used by Hogenboom (2009) for environmental samples to search for emerging water contaminants and by Dervilly-Pinel (2011) to search for metabolic biomarkers adapted to the screening of anabolic steroid treatment in calves. This mass spectrometry-based "metabolomic" strategy opens a new trend in the field of veterinary drug residue control.

In our laboratory, pre-target screening using LC-MS/MS in MRM mode has been developed and validated for the identification of 60 antibiotics all belonging to the main antimicrobial families (i.e. cyclines, penicillins, cephalosporins, macrolides, aminoglycosides, sulfonamides and quinolones) in pig muscle tissues and in cows milk. This method monitors these antimicrobials at their MRL level, employing simple and fast extraction (Hurtaud-Pessel 2008, Gaugain-Juhel 2009). This method is currently being collaboratively assessed in France to be proposed either as a post-screening method leading to formal molecular identification or as an alternative to direct screening with microbiological tests in the national monitoring plan for antibiotic residues in meat products. The objective of the work reported here is first to assess the transfer of this MRM-based method to LC-HRMS and secondly to develop a "post-target" screening method primarily dedicated to penicillins, cephalosporins, sulfonamides, macrolides, tetracyclines, quinolones and aminoglycosides in muscle tissues.

Our work demonstrates that some modifications in sample preparation are necessary to achieve adequate sensitivity of the HRMS signals at the MRL level for some of the tested 
compounds. The sensitivity of the method for the whole set of 60 antimicrobials was assessed through analysis of spiked samples. Automatic data processing using specific software $\left(\operatorname{Toxld}^{\circledR}\right)$ was implemented in order to allow the automatic identification of the compounds through the evaluation of their respective exact mass in combination with their retention times.

\section{Materials and Methods \\ Reagents}

All reagents and solvents used were of analytical grade or HPLC grade. Methanol, trichloroacetic acid (TCA) (analytical grade), formic acid (98-100\% for analysis) and ammonium acetate were purchased from Merck (Darmstadt,Germany). Acetonitrile was obtained from Fisher Scientific (St. Quentin Fallavier, France). Heptafluorobutyric acid (HFBA) was obtained from Fluka (St Quentin Fallavier, France). Water was purified using a Milli-Q-System (Millipore, Molsheim, France).

The standards were obtained from different companies:

- marbofloxacin, norfloxacin, ciprofloxacin hydrochloride, enrofloxacin, difloxacin hydrochloride, oxolinic acid, nalidixic acid, flumequine, spiramycin, tylosin tartrate, tilmicosin, erythromycin, josamycin, amoxicillin, ampicillin sodium, penicillin-G sodium (=benzylpenicillin), Penicillin V (= phenoxymethylpenicillinic acid potassium salt), oxacillin sodium, cloxacillin sodium, dicloxacillin sodium, nafcillin sodium, cephapirin sodium, cefquinome sulfate, cefazolin sodium, cefalonium hydrate, cephalexin hydrate, ceftiofur, cefoperazone sodium, oxytetracyclin hydrochloride, chlortetracyclin hydrochloride, tetracyclin hydrochloride, spectinomycin dihydrochloride, streptomycin sulfate, dihydrostreptomycin sesquisulfate trihydrate, kanamycin sulfate, gentamicin sulfate, neomycin trisulfate hydrate, sulfaphenazole, sulfaguanidine monohydrate, sulfadiazin sodium, sulfathiazole, sulfamethazine, sulfamethoxypyridazin, sulfamonomethoxine, sulfadoxine, sulfaquinoxalin sodium, sulfadimethoxin sodium, sulfamethoxazole and sulfamerazine were purchased from Sigma (St Quentin Fallavier, France).

- Sarafloxacin hydrochloride, doxycyclin hyclate, paromomycin sulfate and apramycin sulfate were obtained from Cluzeau Info Labo (Courbevoie, France), danofloxacin mesylate, tulathromycine and tulathromycine marker from Pfizer (Amboise, France), neospiramycin from Wako (Neuss, Germany) and tylvalosin (=3-O-Acetyltylosin) from Eco (London, United kingdom).

\section{Standards solutions}


Individual stock standard solutions $(0.5 \mathrm{mg} / \mathrm{ml})$ were prepared by dissolving the appropriate amount of each standard into water or methanol according to their solubility: i.e. each penicillin compound in $100 \%$ water; each cephalosporins and aminoglycosides compound in water/methanol $(1 / 1 ; \mathrm{v} / \mathrm{v})$; each compound from tetracycline, macrolide and sulphonamide families in $100 \%$ methanol. Each quinolone compound stock solution was prepared in $1 \mathrm{~N}$ sodium hydroxide/methanol $(1 / 24, \mathrm{v} / \mathrm{v})$. All stock solutions were stored in a dark place at $+4^{\circ} \mathrm{C}$, except the methanolic solutions which were stored at $-20^{\circ} \mathrm{C}$. For spiking, dilute composite standard solutions were also prepared in ultra-pure water to obtain the desired concentrations.

A $1 \mathrm{mM} \mathrm{HFBA}$ and $0.5 \%$ formic acid solution was prepared by diluting $0.065 \mathrm{ml}$ of HFBA and $2.5 \mathrm{ml}$ of formic acid (100\%) to $500 \mathrm{ml}$ of water. A $0.5 \%$ formic acid solution in methanol/acetonitrile $(1 / 1 ; \mathrm{v} / \mathrm{v})$ was prepared by diluting $2.5 \mathrm{ml}$ of pure formic acid to $500 \mathrm{ml}$ with methanol/acetonitrile $(1 / 1 ; \mathrm{v} / \mathrm{v})$. These two solutions were employed as the LC mobile phases $[A]$ and $[B]$ respectively.

A 5\% TCA solution in acetonitrile was prepared by dissolving $10 \mathrm{~g}$ of trichloroacetic acid in a $10 \mathrm{ml}$ volumetric flask and adjusting up to the volume with water, then transferring $2.5 \mathrm{ml}$ of this solution in $45 \mathrm{ml}$ of acetonitrile in a $50 \mathrm{ml}$ volumetric flask and adjusting up to the volume with acetonitrile.

A $5 \%$ TCA solution in water was prepared by dissolving $5 \mathrm{~g}$ of trichloroacetic acid in a $100 \mathrm{ml}$ volumetric flask and adjusting up to the volume with water. A $2 \mathrm{M}$ ammonium acetate solution was prepared by dissolving $15.4 \mathrm{~g}$ of ammonium acetate in $100 \mathrm{ml}$ of water. This solution was then diluted ten times to obtain a $0.2 \mathrm{M}$ solution.

\section{Sample preparation procedures}

To allow extraction of all families of studied compounds, two sample preparations were carried out. Twice a $2 \mathrm{~g}$ amount of minced muscle tissue per sample was accurately weighed and placed into $16 \mathrm{ml}$ centrifuge tubes. Internal standard solution ( $200 \mu \mathrm{l}$ of Sulfaphenazole at $1 \mathrm{mg} . \mathrm{I}^{-1}$ ) and $800 \mu \mathrm{l}$ of water were added to each tube.

Extraction 1: In the first tube, $8 \mathrm{ml}$ of acetonitrile were added to the sample. After rotarystirring for $10 \mathrm{~min}$ at $100 \mathrm{rd} / \mathrm{min}$ and centrifugation at $14,000 \mathrm{~g}$ for $5 \mathrm{~min}, 9 \mathrm{ml}$ of the supernatant were transferred into a clean tube and were evaporated to dryness under a nitrogen stream at $50^{\circ} \mathrm{C}$. The remaining residue was dissolved in $0.5 \mathrm{ml}$ of $0.2 \mathrm{M}$ 
ammonium acetate, mixed by vortexing and then filtered onto a $0.45 \mu \mathrm{m}$ PVDF Millex HV (Millipore) filter of $13 \mathrm{~mm}$ diameter prior to injection.

Extraction 2: In the second tube, $0.5 \mathrm{ml}$ of $5 \%$ TCA solution in water and $7.5 \mathrm{ml}$ of $5 \%$ TCA solution in acetonitrile were added to the sample. After stirring for $10 \mathrm{~min}$ and centrifugation at $14,000 \mathrm{~g}$ for $5 \mathrm{~min}, 7.5 \mathrm{ml}$ of the supernatant was transferred into a new tube and 6-7 drops of $12.5 \% \mathrm{NH}_{4} \mathrm{OH}$ solution were added for neutralization $(\mathrm{pH}=7)$. After centrifugation at $14,000 \mathrm{~g}$ for $5 \mathrm{~min}, 7.5 \mathrm{ml}$ of supernatant was transferred for evaporation at $50^{\circ} \mathrm{C}$ under nitrogen stream until reducing the volume to about $1 \mathrm{ml}$. At this step, another centrifugation at $14,000 \mathrm{~g}$ for $5 \mathrm{~min}$ was performed before to continue the evaporation under nitrogen flow at $50^{\circ} \mathrm{C}$ till about $50-100 \mu \mathrm{l}$. The remaining residue was dissolved in $1 \mathrm{ml}$ of water and loaded onto preconditioned C18 solid phase extraction cartridge (Bond-Elut ${ }^{\circledR}, 200 \mathrm{mg}$ ). After washing the cartridge with $1 \mathrm{ml}$ of water, the elution was carried out with $2 \times 0.7 \mathrm{ml}$ of methanol. The methanolic solution was evaporated to dryness under a gentle stream of nitrogen at $50^{\circ} \mathrm{C}$ and the bottom remaining residue was dissolved in $0.5 \mathrm{ml}$ of $0.2 \mathrm{M}$ ammonium acetate. The final solution was filtered onto a $0.45 \mu \mathrm{m}$ PVDF Millex HV (Millipore) filter of $13 \mathrm{~mm}$ diameter prior to LC injection.

\section{Liquid chromatography-mass spectrometry (LC-LTQ-Orbitrap)}

Chromatographic separations were performed on an Accela liquid chromatography U-HPLC system (ThermoFisher, Bremen, Germany) equipped with a RP18e Purospher column (125 x $3 \mathrm{~mm} ; 5 \mu \mathrm{m}$ particle size) from Merck (Darmstadt, Germany) protected by a RP18e guard column ( $4 \times 4 \mathrm{~mm}, 5 \mu \mathrm{m}$ particle size). The column was kept at a temperature of $25^{\circ} \mathrm{C}$. The flow rate used was $500 \mu \mathrm{L} \cdot \mathrm{min}^{-1}$, and the injection volume was $25 \mu \mathrm{L}$. The mobile phase consisted of $[A] 1 \mathrm{mM} H F B A$ in $0.5 \%$ formic acid solution and $[B] 0.5 \%$ formic acid solution in Methanol/Acetonitrile (50/50; v/v) The elution gradient was linearly ramped from $10 \%$ to $95 \%$ of eluent $B$ for $12 \mathrm{~min}$ and hold at $95 \%$ for $3 \mathrm{~min}$ (12-15 $\mathrm{min}$ ). Then the elution gradient was linearly ramped down to $10 \% \mathrm{~B}$ for $1 \mathrm{~min}$ and maintained for $6 \mathrm{~min}$ to allow column conditioning for the next injection.

Mass spectral analysis was carried out on LTQ-Orbitrap mass spectrometer XL MS (Thermofisher, Bremen, Germany) equipped with an electrospray ionization interface (ESI) and operated in the positive ion mode. The instrument was calibrated using the manufacturer's calibration solution consisting of 3 mass calibrators (i.e. the caffeine, the tetrapeptide MRFA and the Ultramark ${ }^{\circledR}$ ) to reach mass accuracies in the 1-3 ppm range. Parameters of the ion source were as follows: capillary voltage $35 \mathrm{~V}$, ion spray voltage 4.3 $\mathrm{kV}$, tube lens $125 \mathrm{~V}$, capillary temperature $350{ }^{\circ} \mathrm{C}$, sheath gas flow 40 (arbitrary units), 
auxiliary gas flow 10 (arbitrary units) and sweep gas 0 (arbitrary units). Nitrogen was used as the sheath and auxiliary gas in the ion source. The instrument was operated in full scan FTMS over a m/z range of 100-1200 Da at a resolving power of 60,000 (full width at half maximum). The eluent was directed into the source of the mass spectrometer from 1 to 20 min by using a divert valve.

\section{RESULTS AND DISCUSSION}

\section{Method development: Sample pre-treatment, liquid chromatography and high resolution mass detection}

At the screening step, there are at least two issues of significance for successful implementation of the method: first, the preparation of the sample and second the detection technique. The very first challenge is to develop a generic non-selective extraction able to cover a wide range of compounds of different chemical properties. At the same time this extraction must demonstrate a high rate of efficiency in order to get sufficient sensitivity and to reach the required detection limits. This efficient sample preparation must then be combined to a detection technique which is not restrictive, that means sufficiently fit for all possible compounds and which can lead to a response for all compounds at their required target limit. LC-HRMS can match with these requirements for detection. The full scan MS is not restrictive. The only limitation the mass spectrometer holds is the capacity of the compounds forming ions in the ionization source. Of course, the best settings for the ionizing conditions in the source (temperature of source or capillary, flow of gases...) considering a multi-residue method are not those generally proposed to optimize for specific compounds but those which allow satisfactory medium conditions for ionizing all separated compounds entering into the source. The chromatographic separation of the compounds can also become of strategic importance. In our study, the target compounds were all antibacterial veterinary drugs. Among them, penicillins, cephalosporins, sulfonamides, macrolides, tetracyclines, and quinolones are easily ionizable compounds. Many liquid chromatographic conditions take advantage of a formic acid or an acetic acid solution as the aqueous phase and of $\mathrm{MeOH}$ or $\mathrm{ACN}$ as the organic phase to separate these compounds through reversed phase LC analytical columns. In opposite, aminoglycosides are not easily separated in these previously notified conditions and it is one of the reasons why some multi-residue methods developed for monitoring antimicrobial veterinary drug residues do not cover aminoside compounds (Kaufman 2008). The use of ion pairing agents diluted into the LC mobile phase is a common way for increasing the retention of these compounds on a reversed phase LC column (Inchauspe 1987). For this purpose, we previously proposed that the separation of all antibacterials could be achieved by adding pentafluoropropionic acid (PFPA) as the aqueous 
mobile phase instead of formic or acetic acids (Hurtaud-Pessel 2008, Gaugain-Juhel 2009). In the present method, another ion pairing agent was chosen, the heptafluorobutyric acid (HFBA). It is widely accepted by the LC-MS analysts community that the use of PFPA or HFBA may decrease the sensitivity of signals entering the mass spectrometer detector compared to the use of formic acid or acetic acid. But it is also one of the compromises we proposed to provide a fairly good detection for all the targeted antibacterials.

Starting from the sample preparation previously developed in our laboratory (Hurtaud-Pessel 2008 and Gaugain-Juhel 2009), two extraction routes were finally implemented to cover all the 60 antibacterials. The first extraction with acetonitrile followed by an evaporation step was tested and found suitable for macrolides, sulfonamides, penicillins and cephalosporins. The second extraction with 5\% TCA did not fit enough because the sensitivity of the signals was too low for some of the analytes from the tetracycline and the aminoglycoside families. A concentration step was therefore introduced. Extraction in acidic medium, with precipitation of proteins using TCA dissolved in acetonitrile was chosen in order to continue with a concentration step by evaporation of the ACN. Neutralization was then necessary and a further clean-up using SPE was undertaken to reach the target detection level for tetracyclines, aminoglycosides and quinolones.

The list of the monitored compounds is given in table 1. The identification of the compounds is based on their exact mass in positive mode and their corresponding retention time. The high resolving power of the Orbitrap, combined to the high mass accuracy, leads to the requested selectivity to identify a compound using its exact mass. In this method, a resolving power of 60,000 FWHM was chosen for the full scan mass acquisition. This resolution was found excellent even though decreasing it to 30,000 FWHM could also give satisfactory results. When the sample is collected from a complex biological matrix bringing signals to a high background made of a huge number of matrix-generated ions, then specific extracted ion mass chromatogram obtained from the full-scan chromatogram by using a narrow mass window (5 ppm) provides a sharp peak only representative of the asked compound without any other interference. If a higher mass window is used, for example $50 \mathrm{ppm}$ or $100 \mathrm{ppm}$, then much interfering ions appear on the extracted ion mass chromatogram (fig 1).

\section{Methodology of processing acquired data and concept of validation.}

To evaluate the performance of the LC-HRMS screening method developed in our study, some characteristic parameters have been determined. In the field of veterinary drug residues, Commission Decision 2002/657/EC lays down criteria for the validation of analytical methods used for screening or confirmatory purpose. In 2010, a new guideline 
dedicated to the validation of screening methods for the monitoring of residues from veterinary medicines has been edited in order to technically complete the Commission Decision 2002/657/EC. According to the Commission Decision 2002/657/EC, the characteristics of performance to be determined specifically for a qualitative screening method are the detection capability of the method also called $C C \beta$, its selectivity/specificity against various interferences and its applicability/ruggedness/stability. Moreover, it is stated that a method utilized for screening purpose should display a false compliant sample rate lower than $5 \%$. $C C \beta$ is the concentration at which only $\leq 5 \%$ of false compliant results remain possible. In case of analytes with an established regulatory limit (MRL for instance), CC $\beta$ must be less or equal to the regulatory limit. During the validation period, to demonstrate that the $C C \beta$ of the method is in full accordance with the regulatory/action limit, a minimum of 20 different representative samples and a maximum of 60 of them should be tested depending on the level of sensitivity of the method. The more sensitive the method is, the less number of samples to validate. In our study, no complete validation as stipulated in the guidelines has been implemented yet, , but a pre-validation study was undertaken; Only a small number of different bovine muscle samples $(<5)$ have been selected when 20-60 different samples should have been taken from different food-producing animal species.

To assess the method, all targeted antimicrobial compounds of table 1 were tested. The compounds were divided into several groups sorted per family and were spiked at a screening target concentration which corresponds to the MRL level or any other level of interest especially for compound bearing no MRL. Four repetitions were performed for each group. An internal standard, the sulfaphenazole was spiked to each sample prior to the extraction, in order to evaluate the extraction efficiency and to control the retention time and the mass accuracy. From these experiments, all retention times were found stable. For example, the relative standard deviation $(n=56)$ calculated for retention time of the sulfaphenazole internal standard is of $0.34 \%$. The mass accuracy showed also a good stability. The accurate mass measurement of the internal standard sulfaphenazole $(\mathrm{m} / \mathrm{z}$ $315.09102)$ was operated for all the extracted samples $(n=56)$ and the deviation of the measured accurate mass ranged from $-2.0 \mathrm{ppm}$ to $0.03 \mathrm{ppm}$ over a period of 5 days of validation. These mass measurement errors show the high stability of the mass spectrometer and thus allow the use of narrow mass extraction window of $5 \mathrm{ppm}$. This range of experimental mass errors fits quite well with the specifications of the LTQ-Orbitrap given by the constructor for using external calibration (3 ppm).

The data were further processed with $\operatorname{ToxId}^{\circledR}$ software, using a previously created searched list of compounds. This allowed identifying automatically each compound using the 
theoretical exact mass with mass windows of $5 \mathrm{ppm}$, and the expected retention time. All compounds were positively identified in each spiked sample using ToxID when the following criteria were met: RT in accordance with the expected RT, measured accurate mass in accordance with the expected accurate mass with a tolerance of $5 \mathrm{ppm}$, and peak intensity higher than an arbitrary threshold of 10000 . This arbitrary threshold has been established examining chromatograms of blank samples and was the limit chosen to be able to distinguish positive from negative samples. With an intensity lower than $10^{4}$, the peak is considered as an artefact. For sulfonamides, 2 pairs of isobaric compounds sulfamethoxypyridazine and sulfamonomethoxine displaying the same elemental composition, have the same exact mass $\mathrm{MH}^{+}$at $\mathrm{m} / \mathrm{z} 281.07028$. These compounds are differentiated only by their respective retention time at $5.5 \mathrm{~min}$ and $6.1 \mathrm{~min}$ as shown in figure 2. The same situation occurred with sulfadoxine and sulfadimethoxine at $\mathrm{m} / \mathrm{z} 311.08085$ (fig 2), and with tetracycline, epi-tetracycline and doxycycline at $\mathrm{m} / \mathrm{z} 445.16054$ (fig 3). Flumequine at m/z 262.08739 and oxolinic acid at m/z 262.07099 are easily differentiated with a resolution of 60,000 FWHM (fig 4). No antibacterial compounds were detected in any of the blank muscle tissue samples.

The sensitivity of the method was very high for macrolides, quinolones and lincosamides, high for sulfonamides and tetracyclines. For penicillins, cephalosporins and aminoglycosides, the sensitivity was lower but no problem of identification occurred except for penicillin $V$ for which a weak signal is observed. Figure 5 displays the intensity of the signal for the whole set of compounds. The arbitrary threshold set at 10000 was the minimum intensity expected for a possible identification using automatic processing with ToxID. The limits of detection (LOD) were calculated from each compound comparing the intensity of the signal obtained for the spiked samples at the target screening concentration to the threshold of 10000 (Table 1).

\section{Applicability to real samples and no target analysis.}

The applicability of the method was tested on some incurred samples of muscle tissues collected from cows and swine administered veterinary antibiotic treatments. The same samples were also analysed using the LC-MS/MS method in MRM mode. Samples were extracted, analyzed using the LC-HRMS method and processed using Toxld software. In these different samples, sulfadimethoxine, doxycycline, penicillin G, DHS and tulathromycine were detected both using LC-HRMS method and LC-QqQ method. However, no quantification was made in the various samples as the objective of the method was only for screening, even though quantification using LC-HRMS with the Orbitrap system was feasible. The additional advantage of the LC-HRMS method was the opportunity offered to search for 
the presence of additional compounds retrospectively from the full scan spectrum. For example, in one beef muscle, sulfadimethoxine was found and identified using retention time and exact mass. In this sample, comparing chromatograms to the chromatogram of a blank muscle tissue, one other compound was selectively detected at $7.9 \mathrm{~min}$ and $\mathrm{m} / \mathrm{z} 353.09142$. The identification as N4-acetyl-sulfadimethoxine was further confirmed by CID fragmentation experiments and by comparison with chemical standard. This compound was then added to our Toxld processing file. Even if this compound is not regulated and is not displaying antibacterial activity, its detection in animal tissues is the undoubted evidence of an administration of the parent drug to the animal.

\section{Perspective to further confirmation of chemical structures}

From the screening, the further step for definitively confirming an antimicrobial compound has been developed using the LTQ-Orbitrap LC-FTMS instrument. Indeed, the LTQ-Orbitrap $\mathrm{XL}$ offers some other possibilities for example to operate fragmentation of a selected precursor ion either in the linear ion trap (CID) or in the High Collision Dissociation cell (HCD). The detection of product ions can also be performed using either the linear ion trap detector or the Orbitrap detector. Therefore at least three possible ways for obtaining further confirmation of a detected compound could be :

1- CID with detection in ion trap leading to low resolution mass measurement of products ions.

2- CID with detection in Orbitrap leading to high resolution mass measurement of products ions

3- HCD with detection in Orbitrap leading to high resolution mass measurement of products ions.

\section{Conclusions}

The LC-HRMS method reported here has been successfully pre-evaluated for the screening of at least 63 antimicrobial compounds in muscle tissue. In comparison with the targeted LCtriple quadrupole method currently used for screening in our laboratory, this approach using full-scan mass acquisition offers the possibility to analyse retrospectively the sets of data. The application of the method to real-life contaminated samples showed that veterinary drug metabolites which are a proof of veterinary treatment can easily be searched from the data by extracting the exact mass ion chromatograms. Of course these metabolites have to be confirmed and could further be included in the extending list of searched compounds in our ToxID file. In near future, we intend to open this method to other classes of veterinary drugs, like NSAIDs, antiparasitic or anticcoccidial drugs. There is theoretically no limit in the number of compounds to be acquired. Still the limitation in developing a unique multi-class multi- 
residue screening method is the sample preparation, achieving suitable ionization of the compounds and the sensitivity of the signals obtained.

The next issue remaining unsolved is to determine whether the exact mass combined with a retention time are sufficient to unambiguously confirm a compound. Using an LTQ-Orbitrap, fragmentation it is possible either through CID or through HCD devices, and measurement of fragment ions either with low or high resolution. Up to now, there are no criteria laid down in any international Guidelines or in the Commission Decision 2002/657/EC for these new approaches using new HRMS instruments such as TOF or Orbitrap system.

\section{REFERENCES:}

Bohm, D. A., Stachel, C. S., \& Gowik, P. (2009). Multi-method for the determination of antibiotics of different substance groups in milk and validation in accordance with Commission Decision 2002/657/EC. Journal of Chromatography A, 1216(46), 8217-8223.

CRLs' guidelines for the validation of screening methods for residues of veterinary medicines. (2010)

http://ec.europa.eu/food/food/chemicalsafety/residues/lab analysis en.htm

Commission Decision 2002/657/EC of 12 August 2002, Off. J. Eur. Communities, L221, 8-36.

Commission regulation No37/2010 (EU) of 22 december 2009, Off. J. Eur. Communities, L15, 1-72.

Dervilly-Pinel, G., Weigel, S., Lommen, A., Chereau, S., Rambaud, L., Essers, M., Antignac, J.-P., Nielen, M. W. F., \& Le Bizec, B. (2011) Assessment of two complementary liquid chromatography coupled to high resolution mass spectrometry metabolomics strategies for the screening of anabolic steroid treatment in calves. Analytica Chimica Acta, In Press.

Gaudin, V., Hedou, C., Rault, A., \& Verdon, E. Validation of a five plate test, the STAR protocol, for the screening of antibiotic residues in muscle from different animal species according to European Decision 2002/657/EC. Food Additives and Contaminants - Part A Chemistry, Analysis, Control, Exposure and Risk Assessment, 27(7), 935-952.

Gaugain-Juhel, M., Delépine, B., Gautier, S., Fourmond, M. P., Gaudin, V., Hurtaud-Pessel, D., Verdon, E., \& Sanders, P. (2009). Validation of a liquid chromatography-tandem mass spectrometry screening method to monitor 58 antibiotics in milk: A qualitative approach. 
Food Additives and Contaminants - Part A Chemistry, Analysis, Control, Exposure and Risk Assessment, 26(11), 1459-1471.

Gerssen A, Mulder P, De Boer J, Screening of lipophilic marine toxins in shellfish and algae: Development of a library using liquid chromatography coupled to orbitrap mass spectrometry Analytica Chimica Acta 685 (2011) 176-185

Granelli, K., \& Branzell, C. (2007). Rapid multi-residue screening of antibiotics in muscle and kidney by liquid chromatography-electrospray ionization-tandem mass spectrometry. Analytica Chimica Acta, 586(1-2 SPEC. ISS.), 289-295.

Hogenboom, A. C., van Leerdam, J. A., \& de Voogt, P. (2009). Accurate mass screening and identification of emerging contaminants in environmental samples by liquid chromatographyhybrid linear ion trap Orbitrap mass spectrometry. Journal of Chromatography A, 1216(3), 510-519.

Hurtaud-Pessel, D., Gautier, S., Gaugain-Juhel, M., Verdon, E. (2008). Screening of veterinary antibacterial residues in muscle using liquid chromatography-tandem mass spectrometry: method validation. Proceedings of the EuroResidueVI - Conference on residues of veterinary drugs in food, vol 3, 1317-1322.

Inchauspe, G., Delrieu, P., Dupin, P., Laurent, M., Samain, D., (1987). Mechanism of selectivity in ion-pair high performance liquid chromatography of aminoglycoside antibiotics using perfluorinated pairing ions, Journal of chromatography, 404, 53-66.

Kaufmann, A., Butcher, P., Maden, K., \& Widmer, M. (2007). Ultra-performance liquid chromatography coupled to time of flight mass spectrometry (UPLC-TOF): A novel tool for multiresidue screening of veterinary drugs in urine. Analytica Chimica Acta, 586(1-2), 13-21.

Kaufmann, A., Butcher, P., Maden, K., \& Widmer, M. (2008). Quantitative multiresidue method for about 100 veterinary drugs in different meat matrices by sub $2-\mu \mathrm{m}$ particulate high-performance liquid chromatography coupled to time of flight mass spectrometry. Journal of Chromatography A, 1194(1), 66-79.

Kilinc B., Meyer C. and Hilge V., (2007) Evaluation of the EEC four-plate test and Premi test for screening antibiotic residues in trout (Salmo trutta), International Journal of Food Science and Technology 42, pp. 625-628. 
Moulard Y., Bailly-Chouriberry L., Boyer S., Garcia P., Popot M.-A., Bonnaire Y., (2011) Use of Benchtop Exactive High Resolution and High Mass Accuracy Orbitrap Mass Spectrometer for Screening in Horse Doping Control, Analytica Chimica Acta (2010), doi:10.1016/j.aca.2011.01.006

Ortelli, D., Cognard, E., Jan, P., \& Edder, P. (2009). Comprehensive fast multiresidue screening of 150 veterinary drugs in milk by ultra-performance liquid chromatography coupled to time of flight mass spectrometry. Journal of Chromatography B, 877(23), 23632374.

Peters, R. J. B., Bolck, Y. J. C., Rutgers, P., Stolker, A. A. M., \& Nielen, M. W. F. (2009). Multi-residue screening of veterinary drugs in egg, fish and meat using high-resolution liquid chromatography accurate mass time-of-flight mass spectrometry. Journal of Chromatography A, 1216(46), 8206-8216.

Petrovic, M., Gros, M., \& Barcelo, D. (2006). Multi-residue analysis of pharmaceuticals in wastewater by ultra-performance liquid chromatography-quadrupole-time-of-flight mass spectrometry. Journal of Chromatography A, 1124(1-2), 68-81.

Pikkemaat M.G., (2009) Microbial screening methods for detection of antibiotic residues in slaughter animals, Analytical and Bioanalytical Chemistry 395, 893-905

Pikkemaat M.G., Rapallini M.L., Oostra-van Dijk S. and Elferink J.W.A.,(2009) Comparison of three microbial screening methods for antibiotics using routine monitoring samples, Analytica Chimica Acta 637. 298-304.

Skrabakova, Z, O'Halloran J, Van Pelt F, James K, Food contaminant analysis at ultra-high mass resolution:application of hybrid linear ion trap-orbitrap mass spectrometry for the determination of the polyether toxins, azaspiracids, in shellfish, Rapid Commun. Mass Spectrom. 2010; 24: 2966-2974

Stolker, A. A. M., Rutgers, P., Oosterink, E., Lasaroms, J. J. P., Peters, R. J. B., Van Rhijn, J. A., \& Nielen, M. W. F. (2008). Comprehensive screening and quantification of veterinary drugs in milk using UPLC-ToF-MS. Analytical and Bioanalytical Chemistry, 391(6), 23092322. 
Yamada R, Kozono M, Ohmori T, Morimatsu F, Kitayama M (2006), Simultaneous

determination of residual veterinary drugs in bovine, porcine, and chicken muscle using liquid chromatography coupled with electrospray ionization tandem mass spectrometry, Biosci.

Biotechnol. Biochem, 70 (1) 54-65.

http://mc.manuscriptcentral.com/tfac Email: fac@tandf.co.uk 
TABLE 1 List of compounds with their molecular formula, the exact mass of $\mathrm{MH}^{+}$, their expected retention time and the level of fortification.

\begin{tabular}{|c|c|c|c|c|c|c|}
\hline Compound Name & class & $\begin{array}{l}\text { Molecular } \\
\text { formula }\end{array}$ & $\begin{array}{c}\text { Expected } \\
\text { RT } \\
\text { (min) }\end{array}$ & $\begin{array}{c}\text { Exact mass } \\
\text { of } \mathrm{MH}+ \\
(\mathrm{m} / \mathrm{z})\end{array}$ & $\begin{array}{c}\text { Target } \\
\text { screening } \\
\text { concentration } \\
(\mu \mathrm{g} / \mathrm{kg})\end{array}$ & $\begin{array}{c}\text { LOD } \\
\mu \mathrm{g} / \mathrm{kg}\end{array}$ \\
\hline Amoxicillin & Penic & $\mathrm{C}_{16} \mathrm{H}_{19} \mathrm{~N}_{3} \mathrm{O}_{5} \mathrm{~S}_{1}$ & 4.92 & 366.11182 & 50 & 26 \\
\hline Ampicillin & Penic & $\mathrm{C}_{16} \mathrm{H}_{19} \mathrm{~N}_{3} \mathrm{O}_{4} \mathrm{~S}_{1}$ & 6.08 & 350.11690 & 50 & 6 \\
\hline Penicillin G & Penic & $\mathrm{C}_{16} \mathrm{H}_{18} \mathrm{~N}_{2} \mathrm{O}_{4} \mathrm{~S}_{1}$ & 8.75 & 335.10600 & 50 & 11 \\
\hline Penicillin V & Penic & $\mathrm{C}_{16} \mathrm{H}_{18} \mathrm{~N}_{2} \mathrm{O}_{5} \mathrm{~S}_{1}$ & 9.42 & 351.10092 & 25 & * \\
\hline Oxacillin & Penic & $\mathrm{C}_{19} \mathrm{H}_{19} \mathrm{~N}_{3} \mathrm{O}_{5} \mathrm{~S}$ & 9.63 & 402.11182 & 300 & 82 \\
\hline Cloxacillin & Penic & $\mathrm{C}_{19} \mathrm{H}_{18} \mathrm{ClN}_{3} \mathrm{O}_{5} \mathrm{~S}$ & 9.99 & 436.07285 & 300 & 71 \\
\hline Nafcillin & Penic & $\mathrm{C}_{21} \mathrm{H}_{22} \mathrm{~N}_{2} \mathrm{O}_{5} \mathrm{~S}$ & 10.34 & 405.13222 & 300 & 3 \\
\hline Dicloxacillin & Penic & $\mathrm{C}_{19} \mathrm{H}_{17} \mathrm{Cl}_{2} \mathrm{~N}_{3} \mathrm{O}_{5} \mathrm{~S}$ & 10.58 & 470.03387 & 300 & 150 \\
\hline Cephapirin & Cepha & $\mathrm{C}_{17} \mathrm{H}_{17} \mathrm{~N}_{3} \mathrm{O}_{6} \mathrm{~S}_{2}$ & 5.01 & 424.06315 & 50 & 6 \\
\hline Ceftiofur & Cepha & $\mathrm{C}_{19} \mathrm{H}_{17} \mathrm{~N}_{5} \mathrm{O}_{7} \mathrm{~S}_{3}$ & 7.7 & 524.03629 & 200 & 4 \\
\hline Cefquinome & Cepha & $\mathrm{C}_{23} \mathrm{H}_{24} \mathrm{~N}_{6} \mathrm{O}_{5} \mathrm{~S}_{2}$ & 5.15 & 529.13224 & 50 & 4 \\
\hline Cephalonium & Cepha & $\mathrm{C}_{20} \mathrm{H}_{18} \mathrm{~N}_{4} \mathrm{O}_{5} \mathrm{~S}_{2}$ & 5.26 & 459.07914 & $50 / 100^{a}$ & 10 \\
\hline Cefazolin & Cepha & $\mathrm{C}_{14} \mathrm{H}_{14} \mathrm{~N}_{8} \mathrm{O}_{4} \mathrm{~S}_{3}$ & 5.79 & 455.03729 & $50 / 100^{a}$ & 11 \\
\hline Cefalexin & Cepha & $\mathrm{C}_{16} \mathrm{H}_{17} \mathrm{~N}_{3} \mathrm{O}_{4} \mathrm{~S}$ & 6 & 348.10125 & 200 & 18 \\
\hline Cefoperazone & Cepha & $\mathrm{C}_{25} \mathrm{H}_{27} \mathrm{~N}_{9} \mathrm{O}_{8} \mathrm{~S}_{2}$ & 6.38 & 646.14968 & 50 & $*$ \\
\hline Sulfaphenazole & Sulph & $\mathrm{C}_{15} \mathrm{H}_{14} \mathrm{~N}_{4} \mathrm{O}_{2} \mathrm{~S}$ & 7.46 & 315.09102 & 100 & 2 \\
\hline Sulfaguanidine & Sulph & $\mathrm{C}_{7} \mathrm{H}_{10} \mathrm{~N}_{4} \mathrm{O}_{2} \mathrm{~S}$ & 2.61 & 215.05972 & 100 & 40 \\
\hline Sulfadiazine & Sulph & $\mathrm{C}_{10} \mathrm{H}_{10} \mathrm{~N}_{4} \mathrm{O}_{2} \mathrm{~S}$ & 4.12 & 251.05972 & 100 & 10 \\
\hline Sulfathiazole & Sulph & $\mathrm{C}_{9} \mathrm{H}_{9} \mathrm{~N}_{3} \mathrm{O}_{2} \mathrm{~S}_{2}$ & 4.45 & 256.02089 & 100 & 7 \\
\hline Sulfamerazine & Sulph & $\mathrm{C}_{11} \mathrm{H}_{12} \mathrm{~N}_{4} \mathrm{O}_{2} \mathrm{~S}$ & 4.73 & 265.07537 & 100 & 3 \\
\hline Sulphamethoxypyridazine & Sulph & $\mathrm{C}_{11} \mathrm{H}_{12} \mathrm{~N}_{4} \mathrm{O}_{3} \mathrm{~S}$ & 5.5 & 281.07029 & 100 & 2 \\
\hline Sulfamonomethoxine & Sulph & $\mathrm{C}_{11} \mathrm{H}_{12} \mathrm{~N}_{4} \mathrm{O}_{3} \mathrm{~S}$ & 6.15 & 281.07029 & 100 & 4 \\
\hline Sulfadoxine & Sulph & $\mathrm{C}_{12} \mathrm{H}_{14} \mathrm{~N}_{4} \mathrm{O}_{4} \mathrm{~S}$ & 6.43 & 311.08085 & 100 & 1 \\
\hline Sulfaquinoxaline & Sulph & $\mathrm{C}_{14} \mathrm{H}_{12} \mathrm{~N}_{4} \mathrm{O}_{2} \mathrm{~S}$ & 7.69 & 301.07537 & 100 & 5 \\
\hline Sulfadimethoxine & Sulph & $\mathrm{C}_{12} \mathrm{H}_{14} \mathrm{~N}_{4} \mathrm{O}_{4} \mathrm{~S}$ & 7.56 & 311.08085 & 100 & 1 \\
\hline Sulfamethoxazole & Sulph & $\mathrm{C}_{10} \mathrm{H}_{11} \mathrm{~N}_{3} \mathrm{O}_{3} \mathrm{~S}$ & 6.48 & 254.05939 & 100 & 3 \\
\hline Sulfadimerazine & Sulph & $\mathrm{C}_{12} \mathrm{H}_{14} \mathrm{~N}_{4} \mathrm{O}_{2} \mathrm{~S}$ & 5.19 & 279.09102 & 100 & 3 \\
\hline
\end{tabular}




\begin{tabular}{|c|c|c|c|c|c|c|}
\hline Tulathromycin marker & Macro & $\mathrm{C}_{29} \mathrm{H}_{56} \mathrm{O}_{9} \mathrm{~N}_{2}$ & 6.07 & 577.40586 & 100 & 1 \\
\hline Neospiramycin & Macro & $\mathrm{C}_{36} \mathrm{H}_{62} \mathrm{~N}_{2} \mathrm{O}_{11}$ & 6.86 & 699.44264 & 200 & 2 \\
\hline Spiramycin & Macro & $\mathrm{C}_{43} \mathrm{H}_{74} \mathrm{~N}_{2} \mathrm{O}_{14}$ & 7.22 & 843.52128 & 200 & 1 \\
\hline Tulathromycin & Macro & $\mathrm{C}_{41} \mathrm{H}_{79} \mathrm{~N}_{3} \mathrm{O}_{12}$ & 6.8 & 806.57365 & $50 / 100^{a}$ & 1 \\
\hline Tilmicosin & Macro & $\mathrm{C}_{46} \mathrm{H}_{80} \mathrm{~N}_{2} \mathrm{O}_{13}$ & 8.01 & 869.57332 & 50 & 1 \\
\hline Tylosin & Macro & $\mathrm{C}_{46} \mathrm{H}_{77} \mathrm{NO}_{17}$ & 8.72 & 916.52643 & 100 & 1 \\
\hline Erythromycin & Macro & $\mathrm{C}_{37} \mathrm{H}_{67} \mathrm{NO}_{13}$ & 8.77 & 734.46852 & 200 & 1 \\
\hline O-acetyltylosin & Macro & $\mathrm{C}_{48} \mathrm{H}_{79} \mathrm{NO}_{18}$ & 9.08 & 958.53699 & 50 & 1 \\
\hline Josamycin & Macro & $\mathrm{C}_{42} \mathrm{H}_{69} \mathrm{NO}_{15}$ & 9.79 & 828.47400 & $50 / 100^{a}$ & 1 \\
\hline Tyvalosin & Macro & $\mathrm{C}_{53} \mathrm{H}_{87} \mathrm{NO}_{19}$ & 10.41 & 1042.59451 & 50 & 1 \\
\hline Spectinomycin & Amgly & $\mathrm{C}_{14} \mathrm{H}_{24} \mathrm{~N}_{2} \mathrm{O}_{7}$ & 3.9 & 333.16563 & 300 & 62 \\
\hline Streptomycin & Amgly & $\mathrm{C}_{21} \mathrm{H}_{39} \mathrm{~N}_{7} \mathrm{O}_{12}$ & 4.6 & 582.27295 & 500 & 307 \\
\hline Dihydrostreptomycin & Amgly & $\mathrm{C}_{21} \mathrm{H}_{41} \mathrm{~N}_{7} \mathrm{O}_{12}$ & 4.65 & 584.28860 & 500 & 6 \\
\hline Kanamycin & Amgly & $\mathrm{C}_{18} \mathrm{H}_{36} \mathrm{~N}_{4} \mathrm{O}_{11}$ & 5.09 & 485.24533 & 100 & 53 \\
\hline Paramomycin & Amgly & $\mathrm{C}_{23} \mathrm{H}_{45} \mathrm{~N}_{5} \mathrm{O}_{14}$ & 5.37 & 616.30358 & 500 & 8 \\
\hline Gentamicin-C1 & Amgly & $\mathrm{C}_{21} \mathrm{H}_{43} \mathrm{~N}_{5} \mathrm{O}_{7}$ & 5.5 & 478.32353 & $50^{b}$ & 10 \\
\hline Gentamicin-C1A & Amgly & $\mathrm{C}_{19} \mathrm{H}_{39} \mathrm{~N}_{5} \mathrm{O}_{7}$ & 5.5 & 450.29222 & $-b$ & 18 \\
\hline Gentamicin-C2 & Amgly & $\mathrm{C}_{20} \mathrm{H}_{41} \mathrm{~N}_{5} \mathrm{O}_{7}$ & 5.5 & 464.30787 & $-{ }^{b}$ & 1 \\
\hline Neomycin & Amgly & $\mathrm{C}_{23} \mathrm{H}_{46} \mathrm{~N}_{6} \mathrm{O}_{13}$ & 5.58 & 615.31956 & 500 & 99 \\
\hline Apramycin & Amgly & $\mathrm{C}_{21} \mathrm{H}_{41} \mathrm{~N}_{5} \mathrm{O}_{11}$ & 5.37 & 540.28753 & 1000 & $30 \varepsilon$ \\
\hline Lincomycin & Linco & $\mathrm{C}_{18} \mathrm{H}_{34} \mathrm{~N}_{2} \mathrm{O}_{6} \mathrm{~S}$ & 5.48 & 407.22103 & 100 & 1 \\
\hline Oxytetracycline & Tсус & $\mathrm{C}_{22} \mathrm{H}_{24} \mathrm{~N}_{2} \mathrm{O}_{9}$ & 6.12 & 461.15546 & 100 & 2 \\
\hline Tetracycline & Tcyc & $\mathrm{C}_{22} \mathrm{H}_{24} \mathrm{~N}_{2} \mathrm{O}_{8}$ & 6.35 & 445.16054 & 100 & 1 \\
\hline Chlortetracycline & Tcyc & $\mathrm{C}_{22} \mathrm{H}_{23} \mathrm{ClN}_{2} \mathrm{O}_{8}$ & 7.32 & 479.12157 & 100 & 4 \\
\hline Doxycycline & Tcyc & $\mathrm{C}_{22} \mathrm{H}_{24} \mathrm{~N}_{2} \mathrm{O}_{8}$ & 7.81 & 445.16054 & 100 & 2 \\
\hline Epi-Oxytetracycline & Tcyc & $\mathrm{C}_{22} \mathrm{H}_{24} \mathrm{~N}_{2} \mathrm{O}_{9}$ & 6.1 & 461.15546 & 100 & - \\
\hline Epi-tetracycline & Tcyc & $\mathrm{C}_{22} \mathrm{H}_{24} \mathrm{~N}_{2} \mathrm{O}_{8}$ & 6.1 & 445.16054 & 100 & - \\
\hline Epi-chlorotetracycline & Tcyc & $\mathrm{C}_{22} \mathrm{H}_{23} \mathrm{ClN}_{2} \mathrm{O}_{8}$ & 6.5 & 479.12157 & 100 & - \\
\hline Marbofloxacin & Quino & $\mathrm{C}_{17} \mathrm{H}_{19} \mathrm{FN}_{4} \mathrm{O}_{4}$ & 5.9 & 363.14631 & 150 & 1 \\
\hline Norfloxacin & Quino & $\mathrm{C}_{16} \mathrm{H}_{18} \mathrm{~F}_{1} \mathrm{~N}_{3} \mathrm{O}_{3}$ & 6.08 & 320.14050 & 100 & 1 \\
\hline Ciprofloxacin & Quino & $\mathrm{C}_{17} \mathrm{H}_{18} \mathrm{~F}_{1} \mathrm{~N}_{3} \mathrm{O}_{3}$ & 6.18 & 332.14050 & 100 & $\perp$ \\
\hline Danofloxacin & Quino & $\mathrm{C}_{19} \mathrm{H}_{20} \mathrm{FN}_{3} \mathrm{O}_{3}$ & 6.26 & 358.15615 & 100 & 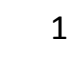 \\
\hline Enrofloxacin & Quino & $\mathrm{C}_{19} \mathrm{H}_{22} \mathrm{FN}_{3} \mathrm{O}_{3}$ & 6.38 & 360.17180 & 100 & 1 \\
\hline Sarafloxacin & Quino & $\mathrm{C}_{20} \mathrm{H}_{17} \mathrm{~F}_{2} \mathrm{~N}_{3} \mathrm{O}_{3}$ & 6.84 & 386.13107 & 200 & 1 \\
\hline
\end{tabular}


1

2

3

4

5

6

7

8

9

10

11

12

13

14

15

16

17

18

19

20

21

22

23

24

25

26

27

28

29

30

31

32

33

34

35

36

37

38

39

40

41

42

43

44

45

46

47

48

49

50

51

52

53

54

55

56

57

58

59

60

\begin{tabular}{lllllll} 
Difloxacin & Quino & $\mathrm{C}_{21} \mathrm{H}_{19} \mathrm{~F}_{2} \mathrm{~N}_{3} \mathrm{O}_{3}$ & 6.83 & 400.14672 & 300 & 1 \\
Oxolinic acid & Quino & $\mathrm{C}_{13} \mathrm{H}_{11} \mathrm{~N}_{1} \mathrm{O}_{5}$ & 7.65 & 262.07100 & 100 & 1 \\
Nalidixic acid & Quino & $\mathrm{C}_{12} \mathrm{H}_{12} \mathrm{~N}_{2} \mathrm{O}_{3}$ & 8.93 & 233.09207 & 100 & 1 \\
Flumequine & Quino & $\mathrm{C}_{14} \mathrm{H}_{12} \mathrm{FNO}_{3}$ & 9.18 & 262.08740 & 200 & 1 \\
\hline
\end{tabular}

Abbreviation of the class $:$ Penic $=$ penicillins $;$ Cepha $=$ cephalosporins; Sulph = sulphonamides; Macro = macrolides, Amgly = aminoglycosides; Linco = lincosamide; Tcycl= tetracyclines; Quino= quinolones. ${ }^{a}$ two levels of fortification were tested for these compounds.

${ }^{\mathrm{b}}$ The spiking solution is prepared from standard of gentamicin containing the three forms $\mathrm{C} 1, \mathrm{C} 1 \mathrm{~A}$ and $\mathrm{C} 2$.

*: not included in the pre-validation study. 


\section{FIGURE CAPTIONS}

Figure 1 : Extraction ion chromatograms of ampicillin $\left(\mathrm{MH}^{+}\right.$at $\left.\mathrm{m} / \mathrm{z} 350.11690\right)$ spiked in bovine muscle at $50 \mu \mathrm{g} / \mathrm{kg}$ with different extraction mass windows a) extraction window : 200 ppm, b) extraction window : $50 \mathrm{ppm}, \mathrm{c}$ ) extraction window : $5 \mathrm{ppm}$

Figure 2 : a) total ion chromatogram obtained from LC-HRMS analysis of a spiked muscle with 12 sulfonamides at $100 \mu \mathrm{g} / \mathrm{kg}$. b) Extracted ion chromatogram of sulfamethoxypyridazine and sulfamonomethoxine at $\mathrm{m} / \mathrm{z} 281.07028$ with extraction window of $5 \mathrm{ppm}$ in spiked muscle at $100 \mu \mathrm{g} / \mathrm{kg} \mathrm{c}$ ) Extracted ion chromatograms of sulfadimethoxine and suldafoxine at $\mathrm{m} / \mathrm{z} 311.08085$ with extraction window of 5 ppm in spiked muscle at 100 $\mu \mathrm{g} / \mathrm{kg}$.

Figure $3:$ a) total ion chromatogram obtained from LC-HRMS analysis of a spiked muscle with tetracyclines and epi-tetracyclines compounds at $100 \mu \mathrm{g} / \mathrm{kg}$. b) Extracted ion chromatogram of ion $\mathrm{MH}^{+}$at $\mathrm{m} / \mathrm{z} 281.07028$ with extraction window of $5 \mathrm{ppm}$ in spiked muscle at $100 \mu \mathrm{g} / \mathrm{kg}$, corresponding to tetracycline, epi-tetracycline and doxycycline.

Figure $4:$ a) total ion chromatogram obtained from LC-HRMS analysis of a spiked muscle with quinolones compounds at level between 100 and $300 \mu \mathrm{g} / \mathrm{kg}$. b) Extracted ion chromatogram of flumequine at $\mathrm{m} / \mathrm{z} 262.08739$ with extraction window of $5 \mathrm{ppm}$ in spiked muscle at $200 \mu \mathrm{g} / \mathrm{kg}$, c) Extracted ion chromatogram of oxolinic acid at m/z 262.07099 with extraction window of $5 \mathrm{ppm}$ in spiked muscle at $100 \mu \mathrm{g} / \mathrm{kg}$.

Figure 5 : Mean signal intensity obtained from each compound spiked in muscle samples $(n=4)$ at level of validation. 


\section{Page 21 of 24}

1

2

5

7

8

9
10

11
12

13

14

15

16

17

18

19

20

21

22

23

24

25

26

27

28

29

30

31

32

33

34

35

36

37

38

39

40

41

42

43

44

45

46

47

48

a) extraction mass window : 200 ppm

b) extraction mass window : $50 \mathrm{ppm}$
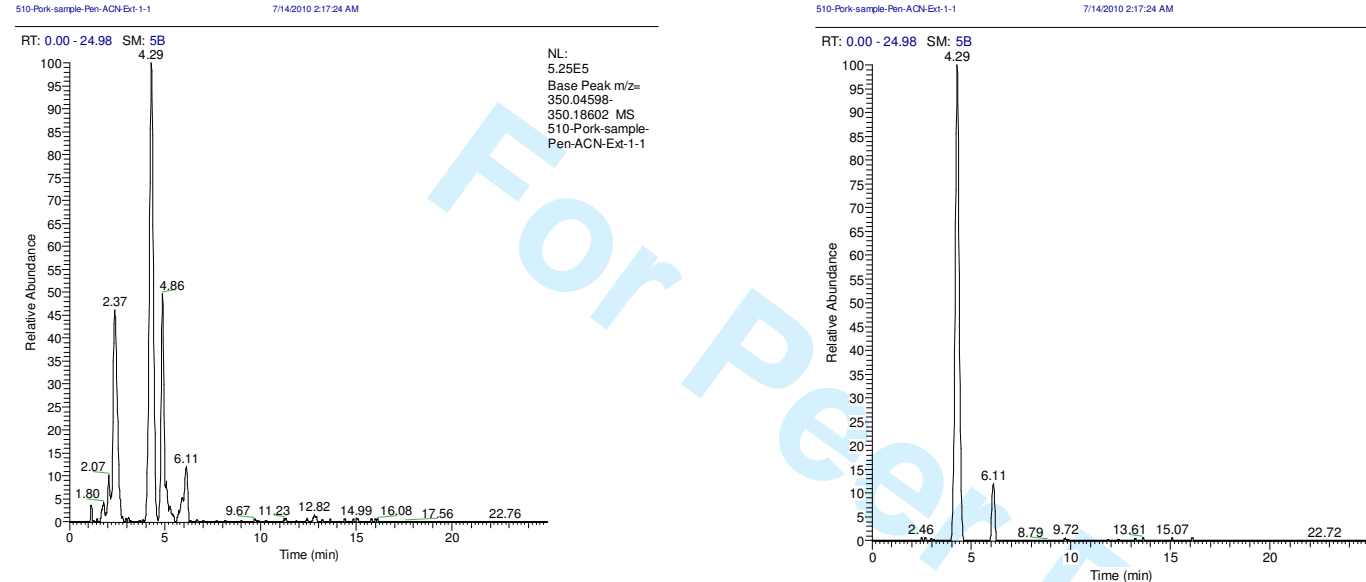

c) extraction mass window: 5 ppm

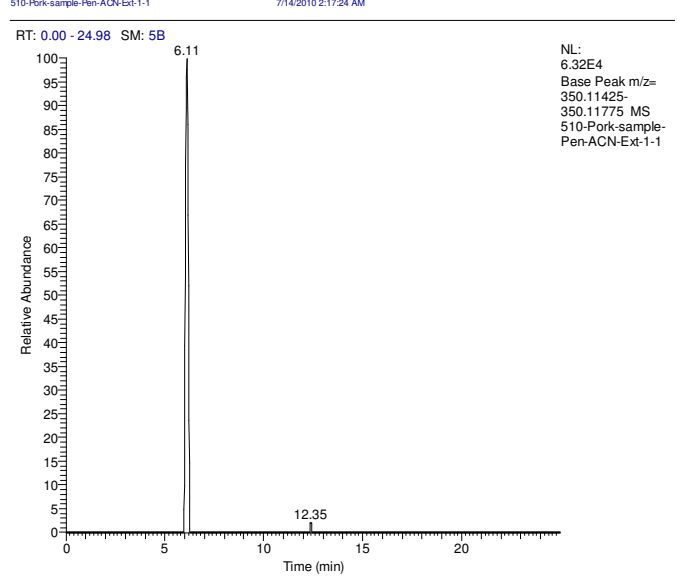


a)

RT: $0.00-24.99$

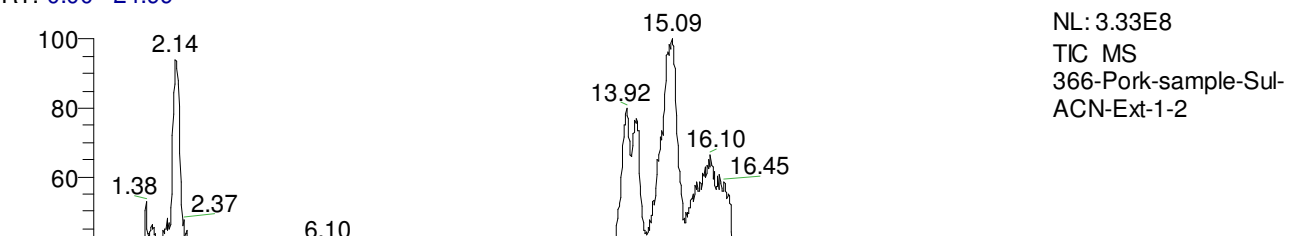

b)

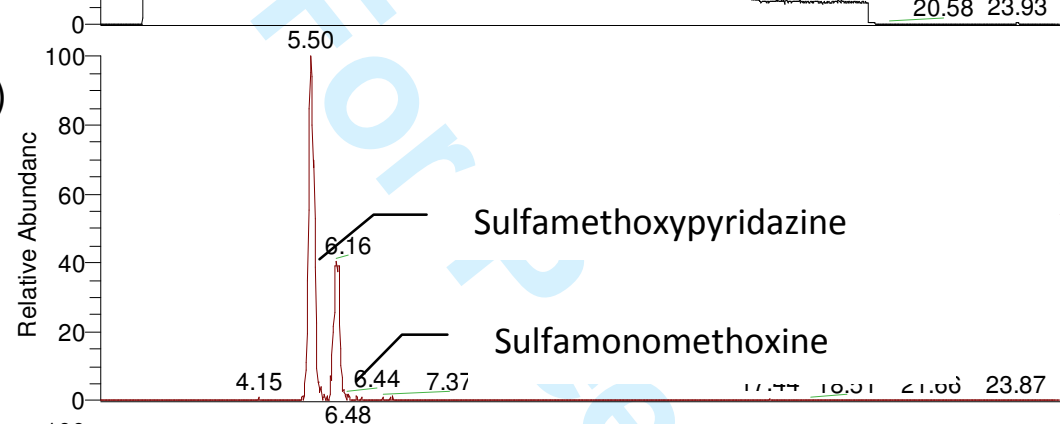

c)

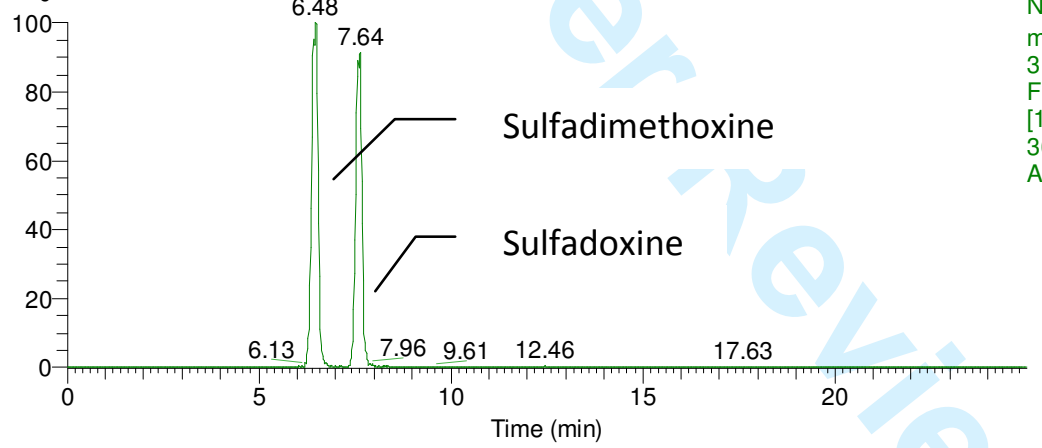

$\mathrm{NL}: 5.47 \mathrm{E} 5$

$\mathrm{m} / \mathrm{z}=$

281.06887-281.07169 F:

FTMS + c ESI Full ms

[100.00-1200.00] MS

366-Pork-sample-Sul-

ACN-Ext-1-2

$\mathrm{NL}: 1.92 \mathrm{E} 6$

$\mathrm{m} / \mathrm{z}=$

.

FTMS + c ESIFull ms

[100.00-1200.00] MS

366-Pork-sample-Sul-

ACN-Ext-1-2

Time (min)

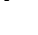

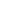
0 


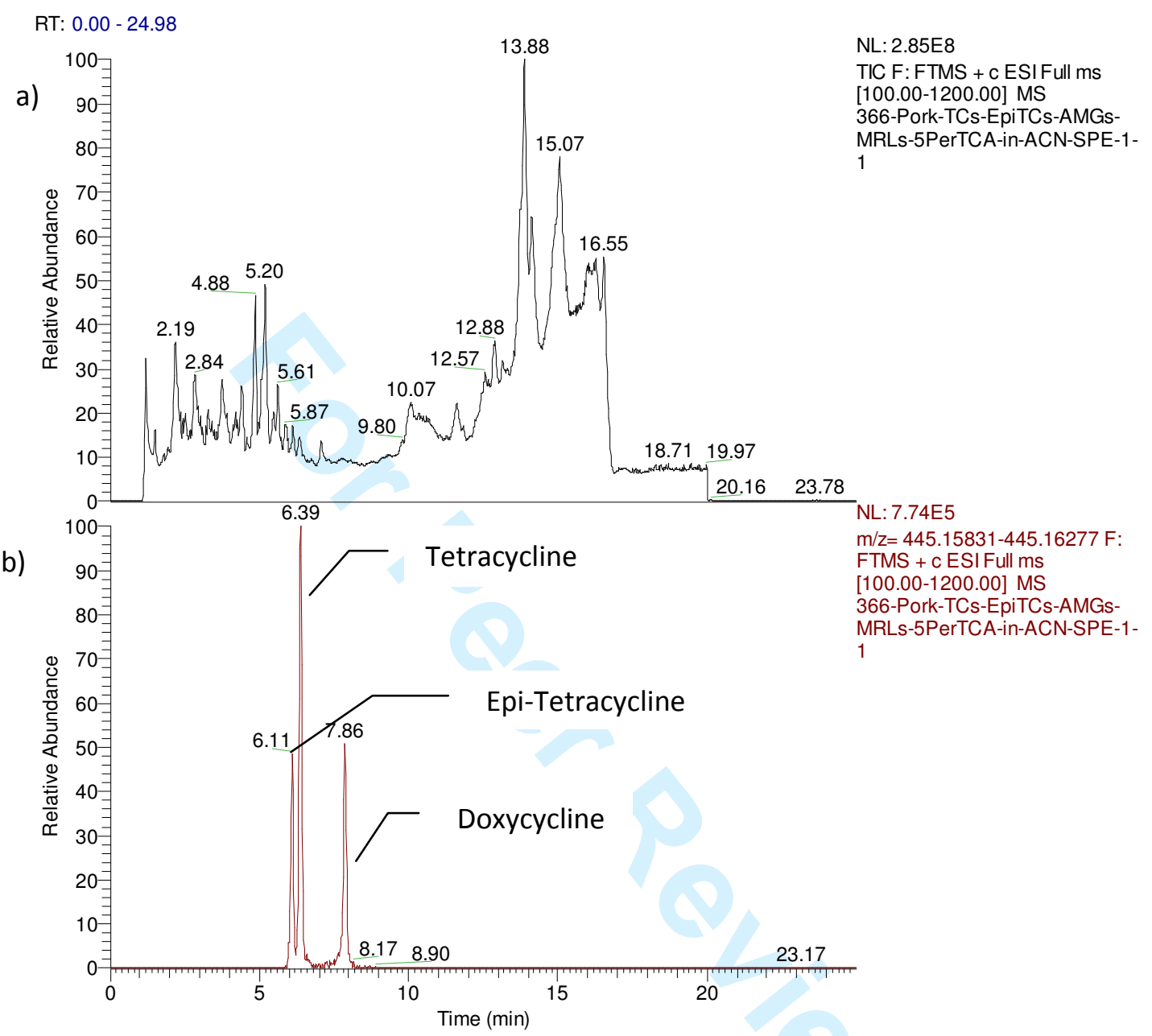


RT: $0.00-24.99$

b)

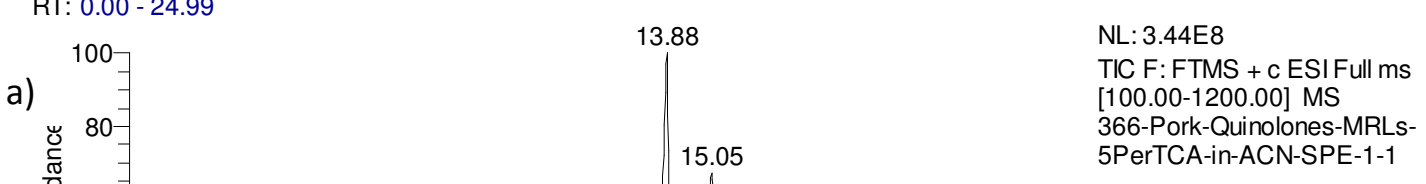

c)
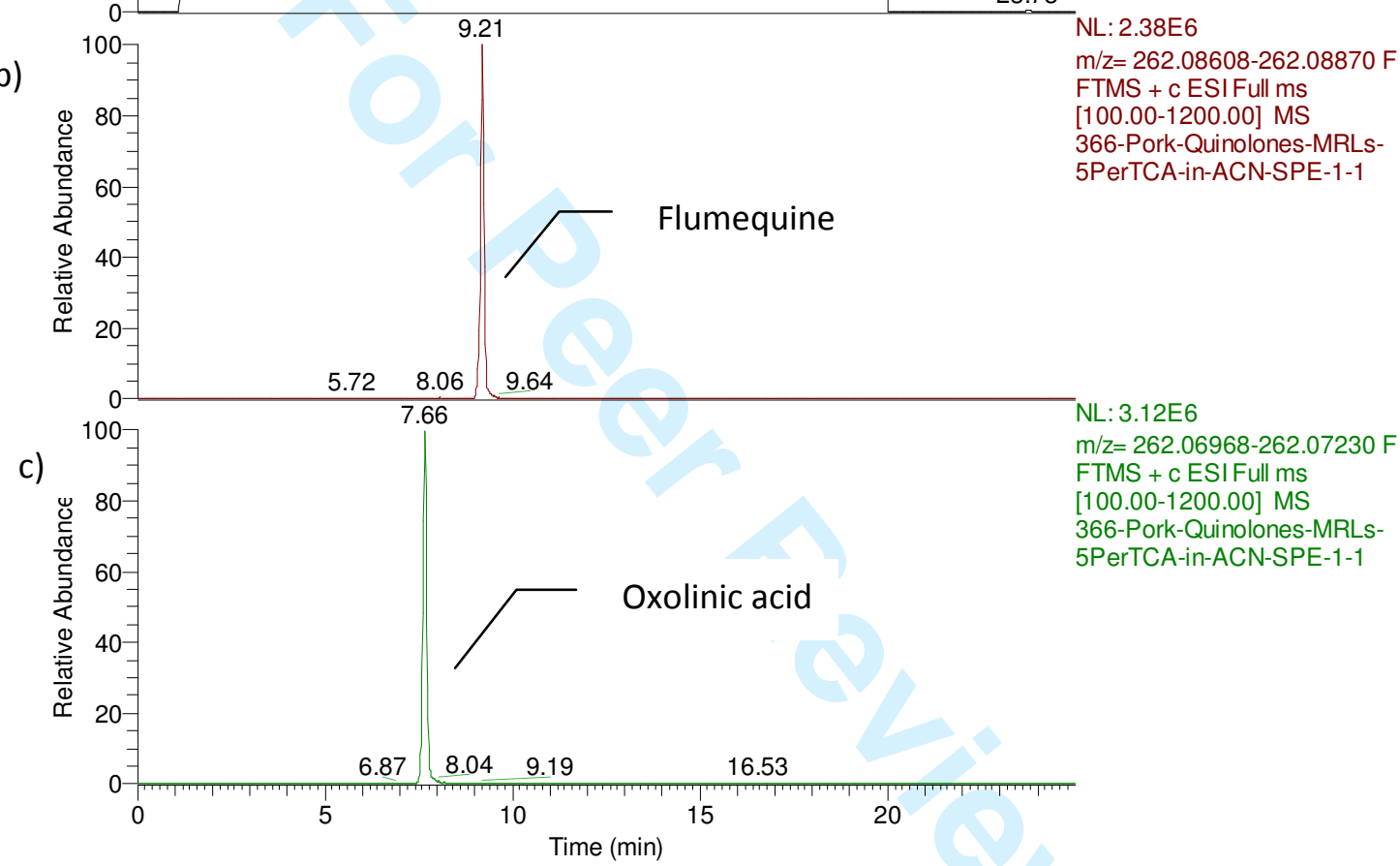

$\mathrm{m} / \mathrm{z}=262.06968-262.07230 \mathrm{~F}$ : FTMS + c ESI Full ms [100.00-1200.00] MS 366-Pork-Quinolones-MRLs5PerTCA-in-ACN-SPE-1-1 


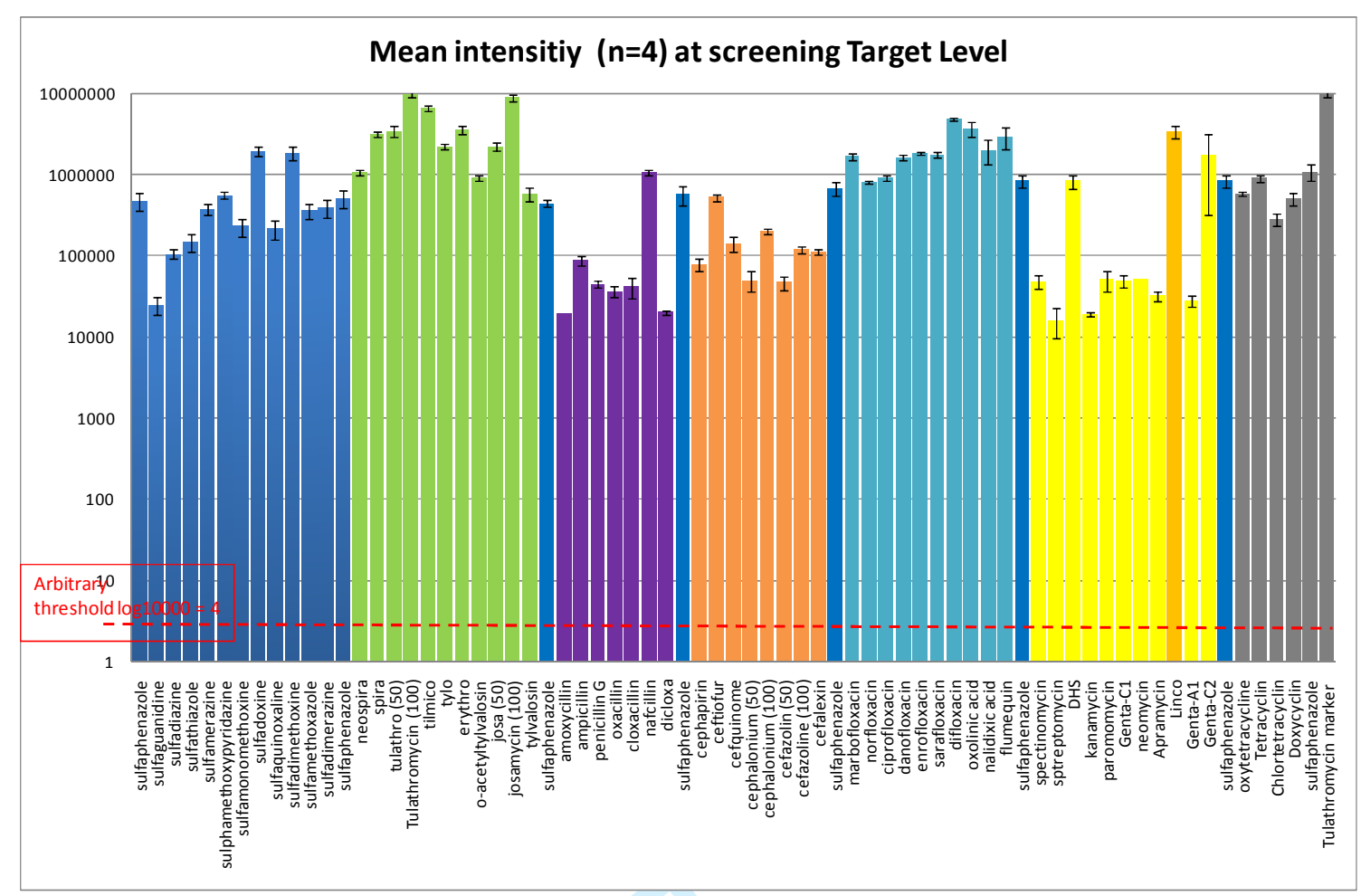

